\title{
Impact of tracheostomy on language and cognitive development in infants with severe bronchopulmonary dysplasia
}

\author{
Betsy Cammack ${ }^{1} \cdot$ Janelle Noel-MacDonnell ${ }^{2} \cdot$ Alain Cuna $^{1} \cdot$ Winston Manimtim $^{1}$
}

Received: 17 April 2019 / Revised: 1 October 2019 / Accepted: 20 October 2019 / Published online: 28 October 2019

(c) The Author(s), under exclusive licence to Springer Nature America, Inc. 2019

\begin{abstract}
Objective The impact of tracheostomy on language and cognitive development in infants with severe bronchopulmonary dysplasia (BPD) is not known. We hypothesize that tracheostomy has an independent negative impact on language and cognitive development in infants with severe BPD.

Study design This is a retrospective cohort study of de-identified data of infants with severe BPD who received tracheostomy at $<2$ years of age, compared with infants with severe BPD without tracheostomy. The primary outcomes measured were total language and cognitive scores at 2-3 years of age as determined by Bayley Scales of Infant and Toddler Development, 3rd Edition. Results A total of 26 patients with tracheostomies and 28 patients without tracheostomies were analyzed. There was no significant difference in total language development or cognitive development between patients with tracheostomies and those without. Insurance status had an effect on language and cognition while controlling for trach status.

Conclusions Tracheostomy does not independently impact the language and cognitive development of infants with severe BPD.
\end{abstract}

\section{Introduction}

Bronchopulmonary dysplasia (BPD), or chronic lung disease of prematurity, is a pulmonary disease of premature infants affecting up to $40 \%$ of infants born prematurely [1]. Despite new and innovative attempts at prevention and treatment, BPD continues to be a notable cause of morbidity and mortality [2-8], with $\sim 5 \%$ of infants with severe BPD requiring tracheostomy [9].

Historically, tracheostomy placement has been utilized primarily for infants with upper airway abnormalities leading to obstruction of breathing $[10,11]$. In more recent years, tracheostomy has been utilized as a means to provide prolonged mechanical ventilation for infants with severe BPD. The development of this practice has led to questions about the long-term outcomes of this population and the

Winston Manimtim

wmmanimtim@cmh.edu

1 Children's Mercy-Kansas City and the University of Missouri-Kansas City School of Medicine, Kansas City, MO 64110, USA

2 Children's Mercy-Kansas City, Kansas City, MO 64108, USA effect of tracheostomy and prolonged ventilation on neurodevelopmental outcomes, particularly language and cognitive development.

Previous studies have examined neurodevelopmental outcomes in very low birthweight infants, extremely low birthweight infants, and infants with BPD (both mild and severe) [2-9, 12]. These studies have demonstrated neurodevelopmental impairment in these infants, most notably in motor skills (both gross and fine), cognitive skills, and language development, when compared with their peers. These studies have also shown worsening neurodevelopmental outcome with increasingly more severe BPD.

An article published in 2014 by the Neonatal Research Network found that infants with tracheostomies had worse developmental outcomes when compared with infants of similar gestational ages [9]. However, this study did not specifically analyze infants with BPD to see whether tracheostomy independently impacted their neurodevelopmental outcomes, but rather looked at overall development, including hearing and vision impairment and cerebral palsy, grouped together with other developmental testing.

To date, no research has been published that directly compares the cognitive and language outcomes of infants with severe BPD who have undergone tracheostomy placement to those with severe BPD who have not undergone 
tracheostomy. We conducted this study to test the hypothesis that infants with severe BPD who receive tracheostomy will have worse language and cognitive outcomes than infants with severe BPD who do not require tracheostomy.

\section{Methods}

This is a retrospective cohort study of infants who received tracheostomy within the first 2 years of life at the level IV intensive care nursery of Children's Mercy Hospital (CMH) in Kansas City, Missouri. This hospital serves as a regional referral center for patients with severe BPD who require evaluation for tracheostomy placement for purposes of prolonged assisted ventilation. For this study, severe BPD was defined as a need for invasive positive pressure, noninvasive positive pressure, continuous positive airway pressure, or high flow nasal cannula with an oxygen requirement of $30 \%$ or more $[1,13]$. The data for this study have been provided by the Center for Infant Pulmonary Disorders (CIPD). The CIPD houses the Infant Pulmonary Disorders Data Repository, which collects de-identified data with CMH Institutional Review Board approval.

Inclusion criteria consisted of all infants born between January 1, 2010 and December 31, 2015 at gestational age of less than 36 weeks and developed severe bronchopulmonary dysplasia (sBPD) and received tracheostomy during their initial hospitalization, for purposes of longterm mechanical ventilation at home, and who were followed after hospital discharge in a designated medical home called the Children's Mercy Infant Tracheostomy and Home Ventilator Clinic. Exclusion criteria were death before hospital discharge, death after discharge prior to reaching 2 years of age, known diagnosis of craniofacial malformations, genetic diagnosis known to cause hearing loss, and infections leading to hearing loss. This cohort was compared with infants hospitalized within the same time period who were born at less than 36 weeks gestation and developed sBPD but were able to wean off mechanical ventilation and did not require tracheostomy. In addition, patients who were tested with a different scale of neurodevelopment were excluded, as those results were not numerically comparable. Patients who attempted bud did not complete the full Bayley testing were excluded as well. The primary outcomes measured were cognitive and total language scores at 2-3 years of age as determined by the Bayley Scales of Infant and Toddler Development, 3rd Edition [14].

Previous studies have validated a mean score of 100 representing average development, with a standard deviation of 15 [14]. Based on validation studies, a score of 85 indicates risk for developmental impairment and a score of 70 indicates profound developmental impairment [2, 15-17].

\section{Data analysis}

Descriptive statistics were calculated for demographic variables, total language and cognitive scores, and other clinical variables. A convenience sample of 54 patients was sufficiently powered to complete $t$-test between the study groups. Comparisons were conducted between patients with tracheostomies and those without them using two-sided independent $t$-test for continuous variables and Chi-Square or Fisher's exact test for categorical variables. Multiple regression analysis was done to determine the impact of patient gender, size at birth (appropriate for gestational age vs small for gestational age), and maternal insurance and maternal education, used as a proxy for socioeconomic status, on both language and cognitive delay. In addition, the level of respiratory support at the time of classification into severe BPD, the airway endoscopy findings and the length of hospital stay were compared between the two groups. All statistical tests were two-sided and conducted at the alpha $=0.05$ level. Statistical analysis was done using SAS software version 9.4 (SAS Institute Inc., Cary, North Carolina, USA).

\section{Results}

Of the 137 infants evaluated for inclusion, 54 infants met criteria to be analyzed for this study. (Fig. 1) Twenty-six patients with tracheostomies and twenty-eight patients without tracheostomies were identified. The results of The Bayley Scales of Infant and Toddler Development, 3rd Edition were analyzed for Language and Cognitive development. Demographics were similar between the two cohorts, tracheostomy vs no tracheostomy, with a statistically significant differences in the following: racial distribution, respiratory support at 36 weeks PMA, presence of tracheobronchomalacia (TBM) diagnosed by bronchoscopy, length of hospital stay, and age at hospital discharge. (Table 1) For each patient cohort, we analyzed the reported range for both total language development and cognitive development. The motor scale scores of development was also reported although this was not part of the primary outcome of interest. We used the numerical composite scores for each of the main scales of development. Each composite score was then used to determine the equivalent qualitative range of impairment such as profound, severe, moderate, borderline, etc., by using the standard psychometric conversion table. There was no significant difference in language composite score between patients with tracheostomies and those without (trachs mean $=75.19$ $(\mathrm{SD}=17.30)$, or median 74 (IQR 59,86) and nontrachs mean $=77.18(\mathrm{SD}=14.08)$, or median $79(\mathrm{IQR} 71,86)$; $p$ value $=0.645$ ). (Table 2 and Fig. 2) The analysis of cognitive development also showed no significant 
Fig. 1 Consort table

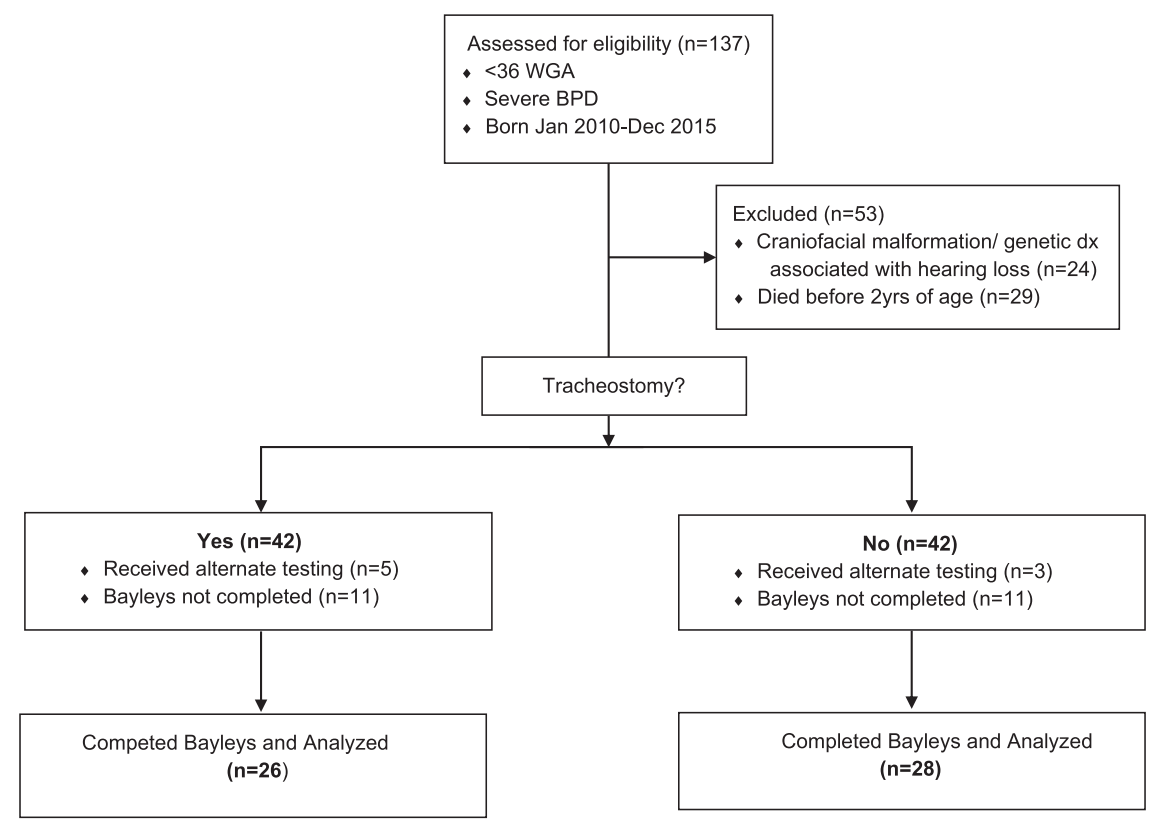

difference (trachs mean $=80.77(\mathrm{SD}=12.70)$, or median $85(\mathrm{IQR}) 75,90)$ and nontrachs mean $=79.64(\mathrm{SD}=11.05)$ or median 80 (IQR) 75, 85); $p$ value $=0.729$ ). (Fig. 2) When the proportion of patients were analyzed based on the qualitative levels of impairment in those with trachs and without trachs, there was no statistical significance between the two groups also (Table 2).

Of note, the majority of patients in both cohorts had profound impairment in all the three scales of development. Using the scale scores for each of the subscales of development, namely, receptive/expressive language and gross/fine motor, there was no statistical difference found between the trach and no trach groups, although there were a number of patients in each group ( 7 for with trachs and 5 for with no trachs) whose scores were not able to be determined.

In the multiple regression analysis, insurance status (either public insurance/no insurance vs private insurance) had an effect on language and cognition composite scores while controlling for trach status ( $p$ value $=0.0291$ for model looking at language composite score and $p$ value $=$ 0.0354 for model looking at cognitive composite score). Higher composite scores for both language and cognition were observed in patients with private insurance. It should also be noted that there was an association between maternal education and insurance status (Fisher's $p$ value $=$ 0.0004).

\section{Discussion}

The data analyzed from this study suggest that a tracheostomy does not significantly impact the language and cognitive development of patients with severe BPD. This is important, as some literature has postulated that the placement of a tracheostomy in an infant or child may independently contribute to neurodevelopmental delay. A study in 2003 suggested that mechanical interference of the tracheostomy tube with vocal cord function may contribute to abnormal language development, and that decannulation at the earliest possible time may ameliorate this effect [18]. It has also been postulated that disruption of airflow across the glottis, Eustachian tube dysfunction, or other causes of hearing loss may contribute to alterations in development of language skills [11]. However, the underlying comorbidities inherent with a diagnosis of severe BPD are not to be discounted. A 2018 secondary analysis of the ELGAN study by Sriram et al. demonstrated consistent intellectual impairment among children at 10 years of age who had a diagnosis of severe BPD on multiple neurocognitive tests [19]. In addition, infants with severe BPD scored lowest in multiple domains, including language and cognitive development [19]. Given this background in combination with our findings, it is reasonable to conclude that severe BPD itself confers developmental impairment, rather than the addition of a tracheostomy.

When comparing the cohort of infants with tracheostomy for severe BPD to those without tracheostomy, we observed several notable findings. First, the age at admission to our institution was significantly different between the two cohorts. This difference is likely due to the nature of the home ventilator program at our institution, which routinely accepts patients from surrounding level III NICUs who have been unable to wean off of positive pressure for various reasons, and ultimately require tracheostomy for long-term mechanical ventilation. 
Table 1 Patient demographics

\begin{tabular}{|c|c|c|c|}
\hline Variables & Tracheostomy $(n=26)$ & No tracheostomy $(n=28)$ & $p$ value \\
\hline Gestational age (weeks) ${ }^{\mathrm{a}}$ & $25(24,28)$ & $26(25,28)$ & 0.267 \\
\hline Birth weight (grams) ${ }^{\mathrm{a}}$ & $743(620,950)$ & $855(760,1022)$ & 0.315 \\
\hline Male $\operatorname{sex}^{\mathrm{b}}$ & $11(42.3 \%)$ & $19(67.9 \%)$ & 0.059 \\
\hline Admission age (days) ${ }^{\mathrm{a}}$ & $68(0,103)$ & $1.5(0,32)$ & 0.006 \\
\hline \multicolumn{4}{|l|}{ Respiratory support at 36 weeks $^{\mathrm{b}}$} \\
\hline Noninvasive (CPAP/NIV) & $7(26.9 \%)$ & $16(57.1 \%)$ & 0.016 \\
\hline Invasive (endotracheal tube) & $14(53.8 \%)$ & $7(25.0 \%)$ & \\
\hline Airway endoscopy ${ }^{\mathrm{b}}$ & $25(96.2 \%)$ & $8(28.6 \%)$ & $<0.001$ \\
\hline Tracheobronchomalacia $^{\mathrm{b}}$ & $10(38.5 \%)$ & $0(0 \%)$ & $<0.001$ \\
\hline Tracheostomy age (PMA, weeks) & $41(38.4,44.1)$ & N/a & \\
\hline Length of stay (days) & $148(105,183)$ & $114(102,125)$ & 0.006 \\
\hline Discharge age (PMA, weeks) ${ }^{\mathrm{a}}$ & $55.8(53,63)$ & $45.6(42,53)$ & $<0.001$ \\
\hline Hearing aids ${ }^{\mathrm{b}}$ & $4(15.4 \%)$ & $1(3.6 \%)$ & 0.184 \\
\hline Tympanostomy tubes ${ }^{b}$ & $3(11.5 \%)$ & $1(3.6 \%)$ & 0.342 \\
\hline Maternal age ${ }^{a}$ & $24(21,30)$ & $29(21.5,32)$ & 0.138 \\
\hline \multicolumn{4}{|l|}{ Highest maternal education $^{\mathrm{b}}$} \\
\hline High school not completed & $1(3.8 \%)$ & $2(7.1 \%)$ & 0.915 \\
\hline High school/GED & $3(11.5 \%)$ & $6(21.4 \%)$ & \\
\hline College & $6(23.1 \%)$ & $5(17.9 \%)$ & \\
\hline Masters & $1(3.8 \%)$ & $0(0 \%)$ & \\
\hline Unknown & $15(57.7 \%)$ & $15(53.6 \%)$ & \\
\hline \multicolumn{4}{|l|}{ Maternal insurance ${ }^{\mathrm{b}}$} \\
\hline Medicaid & $13(50 \%)$ & $20(71.4 \%)$ & 0.134 \\
\hline Private & $12(46.2 \%)$ & $6(21.4 \%)$ & \\
\hline None & $1(3.8 \%)$ & $2(7.2 \%)$ & \\
\hline \multicolumn{4}{|l|}{ Maternal race/ethnicity ${ }^{\mathrm{b}}$} \\
\hline White & $22(84.6 \%)$ & $12(42.9 \%)$ & $<0.001$ \\
\hline Black/African American & $1(3.8 \%)$ & $12(42.9 \%)$ & \\
\hline Hispanic & $0(0 \%)$ & $3(10.7 \%)$ & \\
\hline Other & $2(7.7 \%)$ & $1(3.6 \%)$ & \\
\hline Unknown & $1(3.8 \%)$ & $0(0 \%)$ & \\
\hline
\end{tabular}

CPAP continuous positive airway pressure, $N I V$ noninvasive ventilation, $P M A$ postmenstrual age, GED general education diploma

a Data presented as median (interquartile range)

${ }^{\mathrm{b}}$ Data presented as number (percentage)

Second, the age at discharge was significantly higher for the tracheostomy group than for the control group. Several factors may lead to this difference, including the increased severity of illness in patients requiring tracheostomy, comorbidities, such as BPD-associated pulmonary hypertension and TBM, and the additional burden placed on families to learn the routine cares required to manage an infant with tracheostomy and assisted ventilation in a home setting. Furthermore, it can be challenging to find private duty home nursing for infants with tracheostomy and home ventilation for the population of patients who come from surrounding rural areas. This delay in discharge is not unique to our institution, and was recently highlighted by
Maynard et al., who showed an increase in hospital stay of 35-53 days on average for children with home health care needs, a notable percentage of whom were born preterm and required tracheostomy [20].

Third, this study revealed a gender and race discrepancy in patients who received tracheostomy for severe BPD, with the largest proportion white and female. Prior studies, such as a prospective cohort study by Keller et al. and a retrospective chart review by Strang et al. demonstrated white infants as the largest proportion of tracheostomy recipients [21]. However, both studies showed a greater proportion of male infants than female infants who received tracheostomy. The difference shown in our study may be due to the 
Table 2 Results of Bayley Scales of Infant and Toddler Development

\begin{tabular}{|c|c|c|c|}
\hline Domain & $\begin{array}{l}\text { Tracheostomy } \\
(n=26)\end{array}$ & $\begin{array}{l}\text { No tracheostomy } \\
(n=28)\end{array}$ & $p$ value \\
\hline Cognitive score ${ }^{a}$ & $85(75,90)$ & $80(75,85)$ & 0.729 \\
\hline \multicolumn{4}{|l|}{$\begin{array}{l}\text { Cognitive } \\
\text { impairment }^{\mathrm{b}}\end{array}$} \\
\hline Profound & $11(42.3 \%)$ & $13(46.4 \%)$ & \multirow[t]{3}{*}{0.448} \\
\hline Severe & $6(23.1 \%)$ & $10(35.7 \%)$ & \\
\hline Moderate & $9(34.6 \%)$ & $5(17.9 \%)$ & \\
\hline Language score ${ }^{\mathrm{a}}$ & $74(59,86)$ & $79(71,86)$ & 0.645 \\
\hline \multicolumn{4}{|l|}{$\begin{array}{l}\text { Language } \\
\text { impairment }^{\text {b }}\end{array}$} \\
\hline Profound & $17(65.4 \%)$ & $18(64.3 \%)$ & \multirow[t]{4}{*}{0.317} \\
\hline Severe & $5(19.2 \%)$ & $6(21.4 \%)$ & \\
\hline Moderate & $2(7.7 \%)$ & $4(14.3 \%)$ & \\
\hline Borderline & $2(7.7 \%)$ & $0(0 \%)$ & \\
\hline Motor score $^{\mathrm{a}}$ & $76(70,85)$ & $85(78,88)$ & 0.217 \\
\hline \multicolumn{4}{|l|}{$\begin{array}{l}\text { Motor } \\
\text { impairment }^{\mathrm{b}}\end{array}$} \\
\hline Profound & $15(57.7 \%)$ & $12(42.9 \%)$ & \\
\hline Severe & $7(26.9 \%)$ & $11(39.3 \%)$ & \multirow[t]{3}{*}{0.672} \\
\hline Moderate & $3(11.5 \%$ & $5(17.9 \%)$ & \\
\hline Borderline & $1(3.8 \%)$ & $0(0 \%)$ & \\
\hline $\begin{array}{l}\text { Receptive } \\
\text { language score }\end{array}$ & $7(5,9)$ & $6(6,8)$ & 0.237 \\
\hline $\begin{array}{l}\text { Expressive } \\
\text { language score }\end{array}$ & $5(2,7)$ & $7(4,7)$ & 0.265 \\
\hline $\begin{array}{l}\text { Gross motor } \\
\text { score }^{c}\end{array}$ & $7(4,7)$ & $7(6,8)$ & 0.296 \\
\hline Fine motor score ${ }^{c}$ & $8(5,8)$ & $8(7,9)$ & 0.406 \\
\hline $\begin{array}{l}\text { Age at testing } \\
\text { (months) }\end{array}$ & $25.5(23,28)$ & $26.5(25,28)$ & 0.765 \\
\hline
\end{tabular}

${ }^{a}$ Composite scores reported in median (interquartile range) for the three main scales (cognitive, language and motor)

${ }^{\mathrm{b}}$ Qualitative range of impairment based on psychometric conversion table, reported in number (\%)

${ }^{\mathrm{c}} \mathrm{Scale}$ scores reported as median (interquartile range) for the subscales of receptive/expressive language and gross/fine motor (with missing data for 7 with tracheostomy and 5 with no tracheostomy)

referral base, which is predominantly white, or may simply be due to artifact from the relatively small sample size. A larger cohort may more accurately depict representative demographics.

Evaluation of the respiratory support required by each cohort is notable for the requirement of intubation for more infants with tracheostomy at 36 weeks' postmenstrual age. It is a logical conclusion that the infants who required tracheostomy were more ill, and therefore required a higher level of respiratory support. This respiratory support difference highlights a larger proportion of infants who did not require tracheostomy who remained on positive pressure (either continuous positive airway pressure or noninvasive
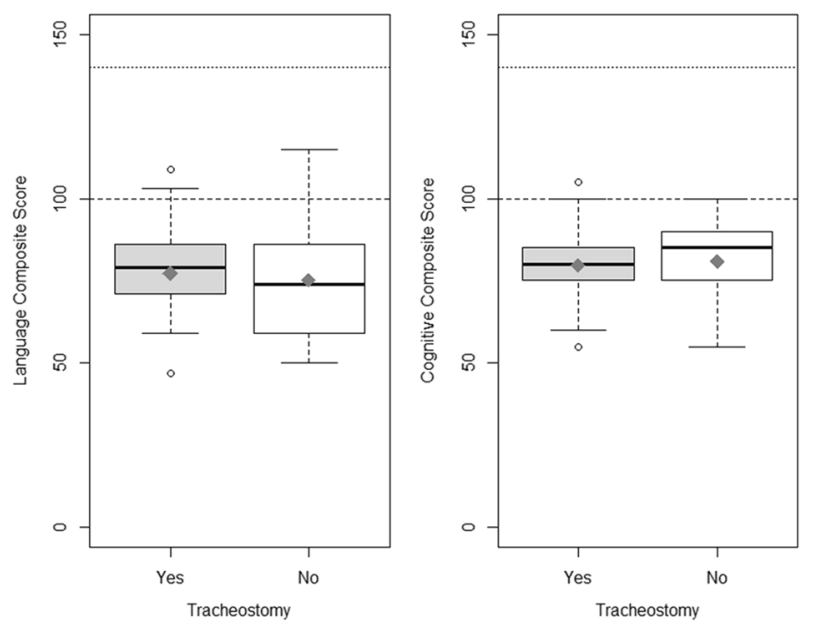

Fig. 2 a Box and whisker plot for total language score. b Box and whisker plot for total cognitive score on Bayley. Horizontal dashed line represents the standardized mean score. Horizontal dotted line represents the highest possible score

positive pressure ventilation) rather than requiring intubation at this same PMA. Of note, all infants who required nasal cannula required either high flow nasal cannula or $>30 \% \mathrm{FiO}_{2}$ to meet the definition of severe $\mathrm{BPD}$ at 36 weeks' PMA. Although there is no consensus as to the appropriate timing for tracheostomy placement in infants with severe BPD, the median age for tracheostomy placement for our cohort was 41 ((IQR) 38.4, 44.1) weeks PMA, which is comparable with most regional centers.

Recently, the contribution of acquired airway abnormalities such as TBM in infants with severe BPD has been recognized. Hysinger et al. found that $36.2 \%$ of infants with BPD has TBM by bronchoscopy. When compared with a cohort of those BPD infants without TBM, infants with TBM had longer and more complicated hospitalizations, and need for prolonged mechanical ventilation [22]. Although our cohort is much smaller in number, the proportion of those with TBM is almost the same, (i.e., 38.5\%). These infants with TBM in our cohort are more likely to receive tracheostomy for long-term ventilation.

The multiple regression analysis highlights the impact of maternal education and maternal insurance, used here as a surrogate for socioeconomic status, on neurodevelopmental outcomes in infants with severe BPD. Patra et al. demonstrated that the negative impact of lower levels of maternal education on cognitive, language, and motor outcomes in infants born preterm when evaluated at 2 years of age [23].

Socioeconomic disadvantage was shown to negatively impact neurodevelopment though early childhood by Hung et al. who concluded that the impact lasts at least through the beginning years of schooling [24]. This finding is consistent with the previously published literature that 
identified both maternal education and socioeconomic status as predictive factors for infant development $[25,26]$.

\section{Strengths of this study}

This study was a targeted analysis of development in infants with the most severe phenotype of BPD, an analysis which has previously been completed secondarily. Since infants in both cohorts were cared for in the same NICU at the time of tracheostomy placement, one can conclude that the decision of whether or not to place a tracheostomy was made by the same physician groups. However, many patients were transferred to our center after hospitalization at outlying level III NICUs, with potentially different management prior to the time of transfer. This may represent a heterogeneous treatment paradigm for these patients, potentially impacting their ultimate need for tracheostomy. All patients identified were followed outpatient by the same institution, and had developmental testing done by two dedicated clinicians, limiting the potential for interpretation bias.

\section{Limitations of this study}

There were a number of patients in both cohorts who had neurodevelopmental testing done using an alternative tool who were not analyzed as results between different tests are not directly comparable. Patients in both cohorts were lost to follow up prior to neurodevelopmental testing may represent a subset who had "normal" outcomes and were not captured. It is worth noting that abstraction of the data for this project identified several patients from both groups who were unable to complete the subscale tests for receptive/expressive language and gross/fine motor components due to severe neurocognitive impairment and there may be a difference in outcome that could not be identified.

Some recent literature suggests that Bayley III overestimates development. However, the comparison in this study showed no difference, suggesting that the two cohorts are equivalent. This is a very important observation as there is a growing evidence that suggests that chronic ventilation via a tracheostomy is beneficial to support the growth and development of infants with severe BPD [27]. When chronic respiratory insufficiency limits the BPD infant's ability to grow and develop, chronic invasive ventilation through a tracheostomy may be a better option to facilitate neurodevelopmental progress and may lead to an improved long-term outcome. Lastly, we were unable to control for intensity of outpatient therapies, which may differ between the two cohorts due to the Infant Home Ventilator program at Children's Mercy, which provides a robust and structured multidisciplinary approach to therapeutic follow up.

In conclusion, we found that infants with severe BPD requiring tracheostomy had no significant difference in language and cognitive development as compared with infants with severe BPD who did not require tracheostomy. A multicenter collaboration with a larger cohort is needed to further validate our findings.

\section{Compliance with ethical standards}

Conflict of interest The authors declare that they have no conflict of interest.

Publisher's note Springer Nature remains neutral with regard to jurisdictional claims in published maps and institutional affiliations.

\section{References}

1. Higgins RD, Jobe AH, Koso-Thomas M, Bancalari E, Viscardi RM, Hartert TV, et al. Bronchopulmonary dysplasia: executive summary of a workshop. J Pediatrics. 2018;197:300-8. https://doi. org/10.1016/j.jpeds.2018.01.043

2. Fernandes LV, Goulart AL, Santos AMND, Barros MCDM, Guerra CC, Kopelman BI. Neurodevelopmental assessment of very low birth weight preterm infants at corrected age of 18-24 months by Bayley III scales. J Pediatr. 2012;88:471-8. https://doi. org/10.1590/S0021-75572012000600005

3. Gregoire M-C, Lefebvre F, Glorieux J. Health and developmental outcomes at 18 months in very preterm infants with bronchopulmonary dysplasia. Pediatrics. 1998;101:856-60. https://doi. org/10.1542/peds.101.5.85

4. Majnemer A, Riley P, Shevell M, Birnbaum R, Greenstone H, Coates AL. Severe bronchopulmonary dysplasia increases risk for later neurological and motor sequelae in preterm survivors. Dev Med Child Neurol. 2000;42:53-60. https://doi.org/10.1111/j. 1469-8749.2000.tb00025

5. Moon NM, Mohay HA, Gray PH. Developmental patterns from 1 to 4 years of extremely preterm infants who required home oxygen therapy. Early Hum Dev. 2007;83:209-16. https://doi.org/10. 1016/j.earlhumdev.2006.05.015

6. Short EJ, Kirchner HL, Asaad GR, Fulton SE, Lewis BA, Klein $\mathrm{N}$, et al. Developmental sequelae in preterm infants having a diagnosis of bronchopulmonary dysplasia. Arch Pediatrics Adolesc Med. 2007;161:1082-7. https://doi.org/10.1001/archpedi. 161.11.1082

7. Singer L, Yamashita T, Lilien L, Collin M, Baley J. A longitudinal study of developmental outcome of infants with bronchopulmonary dysplasia and very low birth weight. Pediatrics. 1997;100:987-93.

8. Trittmann JK, Nelin LD, Klebanoff MA. Bronchopulmonary dysplasia and neurodevelopmental outcome in extremely preterm neonates. Eur J Pediatrics. 2013;172:1173-80. https://doi.org/10. 1007/s00431-013-2016

9. DeMauro SB, D’Agostino JA, Bann C, Bernbaum J, Gerdes M, Bell EF, et al. Developmental outcomes of very preterm infants with tracheostomies. J Pediatrics. 2014;164:1303-10. https://doi. org/10.1016/j.jpeds.2013.12.014

10. Walsh J, Rastatter J. Neonatal tracheostomy. Clin Perinatol. 2018;45:805-16. https://doi.org/10.1016/j.clp.2018.07.014

11. DeMauro SB, Wei JL, Lin RJ. Perspectives on neonatal and infant tracheostomy. Semin Fetal Neonatal Med. 2016;285-91. https:// doi.org/10.1016/j.siny.2016.03.006

12. Månsson J, Stjernqvist K. Children born extremely preterm show significant lower cognitive, language and motor function levels compared with children born at term, as measured by the Bayley- 
III at 2.5 years. Acta Paediatrica. 2014;103:504-11. https://doi. org/10.1111/apa.12585

13. Jobe AH, Bancalari E. Bronchopulmonary dysplasia. Am J Respir Crit Care Med. 2001;163:1723 https://doi.org/10.1164/ajrccm. 163.7.2011060

14. Bayley N. Bayley scales of infant and toddler development, 3rd ed. Administration manual. San Antonio, TX: Harcourt; 2006. https://doi.org/10.1177/0734282906297199

15. Johnson S, Moore T, Marlow N. Using the Bayley-III to assess neurodevelopmental delay: which cut-off should be used? Pediatr Res. 2014;75:670-4. https://doi.org/10.1038/pr.2014.10

16. Santos ESLD, Kieviet JFD, Königs M, Elburg RMV, Oosterlaan J. Predictive value of the Bayley Scales of Infant Development on development of very preterm/very low birth weight children: a meta-analysis. Early Hum Dev. 2013;89:487-96. https://doi.org/ 10.1016/j.earlhumdev.2013.03.008

17. Spencer-Smith MM, Spittle AJ, Lee KJ, Doyle LW, Anderson PJ. Bayley-III cognitive and language scales in preterm children. Pediatrics. 2015;135:1258-65. https://doi.org/10.1542/peds.2014-3039

18. Jiang D, Morrison GAJ. The influence of long-term tracheostomy on speech and language development in children. Int J Pediatr Otolaryngol. 2003;67:217-20. https://doi.org/10.1016/j.ijporl.2003.08.031

19. Sriram S, Schreiber MD, Msall ME, Kuban KCK, Joseph RM, O'Shea TM, et al. Cognitive development and quality of life associated with BPD in 10-year-olds born preterm. Pediatrics. 2018;141:e20172719 https://doi.org/10.1542/peds.2017-2719

20. Maynard R, Christensen E, Cady R, Jacob A, Ouellette Y, Podgorski $\mathrm{H}$, et al. Home health care availability and discharge delays in children with medical complexity. Pediatrics. 2019;143: e20181951 https://doi.org/10.1542/peds.2018-1951
21. Strang AR, Briddell JW, Barth PC, Shah UK, Chidekel A. Risk factor analysis for mortality among infants requiring tracheostomy. Pediatr Pulmonol. 2018;53:1115-21. https://doi.org/10. 1002/ppul.24064

22. Hysinger E, Friedman N, Padula M, Shinohara R, Zhang H, Panich $\mathrm{H}$, et al. Tracheobronchomalacia is associated with increased morbidity in bronchopulmonary dysplasia. Ann Am Thorac Soc. 2017;14:1428-35. https://doi.org/10.1513/Anna 1sATS.201702-1780C

23. Patra K, Greene MM, Patel AL, Meier P. Maternal education level predicts cognitive, language, and motor outcome in preterm infants in the second year of life. Am J Perinatol. 2016;33:738-44. https://doi.org/10.1055/s-0036-1572532

24. Hung GCL, Hahn J, Alamiri B, Buka SL, Goldstein JM, Laird N, et al. Socioeconomic disadvantage and neural development from infancy through early childhood. Int J Epidemiol. 2015; 44:1889-99. https://doi.org/10.1093/ije/dyv303

25. Asztalos EV, Church PT, Riley P, Fajardo C, Shah PS. Association between primary caregiver education and cognitive and language development of preterm neonates. Am J Perinatol. 2017;34:364-71. https://doi.org/10.1055/s-0036-1592080

26. Ronfani L, Brumatti LV, Mariuz M, Tognin V, Bin M, Ferluga V, et al. The complex interaction between home environment, socioeconomic status, maternal IQ and early child neurocognitive development: a multivariate analysis of data collected in a newborn cohort study. PLoS ONE. 2015;10. https://doi.org/10.1371/ journal.pone.0127052

27. Baker CD. Long-term ventilation for children with chronic lung disease of infancy. Curr Opin Pediatr. 2019;31:357-66. https:// doi.org/10.1097/MOP.0000000000000757 